\title{
Carousel frauds in the Czech Republic
}

\author{
Alexej Sato \\ Department of International Trade, University of Economics, Prague, Czech Republic
}

Email address:

sato@vse.cz

\section{To cite this article:}

Alexej Sato. Carousel Frauds in the Czech Republic. Journal of Finance and Accounting. Special Issue: Emerging trends in Finance and Accounting. Vol. 2, No. 6-2, 2014, pp. 1-5. doi: 10.11648/j.jfa.s.2014020602.11

\begin{abstract}
Collection of value added tax represents for all EU Member States an important part of the state budget, the share of which is mostly higher than $20 \%$. Growing state expenses and endless economic and financial crisis have resulted in deep dependence on EU Member States revenues from VAT. Organized groups of tax fraudsters abuse the loopholes in current tax legislation to achieve unjust enrichment. This paper describes the practices of tax frauds in VAT collection most frequently used in the Czech Republic, summarizes measures adopted by tax administration and evaluates the effectiveness of their application.
\end{abstract}

Keywords: Taxation, VAT Collection, State Budget, Carousel Fraud

\section{Introduction}

Taxation in trade between EU Member States as well as in trade with the third countries outside the EU is based on the principle so-called reverse charge. Reporting and collection of value added tax imposed on the sale of goods or services are not obligations of the supplier, as in domestic trade, but the responsibility of the purchaser or recipient. ${ }^{1}$ A reversed tax regime allows purchasers of goods or recipients of services to report and tax them locally, without the complicated necessity of claiming tax deduction or even authorizing payment of value added tax in a foreign country.

Collection of value added tax represents for all EU Member States an important part of the state budget, the share of which is mostly higher than $20 \%$. Growing state expenses and endless economic and financial crisis have resulted in deep dependence of EU Member States on revenues from VAT. The majority of EU Member States either has increased the VAT rate or is considering their increase in the nearest future. Tax collection through VAT is also far more effective than through direct taxes, because a great part of the costs associated with tax accessing is paid by the taxpayers themselves. VAT collection usually has less influence on the productive sector than consumption.

The roots of the current system of reporting and collection of VAT date back to the 1960s. This tax system does not manage to follow current rapid economic and geopolitical development, significantly lags behind improvements in information systems and technology and puts a heavy administrative burden on both business and the public sector, despite the efforts of national and EU competent authorities on its modernization and harmonization.

The European Commission has been pursuing the removal of barriers to the single internal market and reduction of administrative barriers. However, agenda related to the reporting and collection of VAT still represents up to $60 \%$ of the administrative tasks in tax administration. Shortages in the current tax system create serious obstacles especially for the activities of small and medium enterprises and burden the public sector as well. Increased tax evasion, particularly in the form of so-called carousel frauds, has caused for example in 2006 within the EU Member States a tax loss totaling an amount estimated 106.7 billion $€$. The real collection of VAT in the EU Member States was about 12\% lower than it should have been (even $20 \%$ or more in some Member States). ${ }^{2}$

There are plenty of causes of arrears of value added tax. The most serious is considered the existence of different tax brackets and rates in the systems used in the Member States, complemented by numerous exceptions. Unfortunately these shortcomings are not resolvable in the foreseeable future. Significant imperfections, however, can be found in the practical application of tax law and prescriptions relating to collection of taxes and subsequent controlling. The current global economic situation is pushing entrepreneurs to obtain financial advantage by using methods that are not in compliance with applicable regulations and that lead in its consequences to significant economic losses. Implementation of so-called carousel business transactions can be considered 
such conduct.

\section{Research Methodology}

The taxation system based on added value was largely introduced worldwide in the second half of the last century. However the system did not prove to be resistant and transparent, as was anticipated, but showed some weaknesses that have enable tax evasion. The most significant imperfections are related to VAT collection and are described as "missing trader frauds" and "carousel frauds". ${ }^{34}$ This problem had not been given much attention until the outbreak of the global financial crisis, when most EU Member States began to experience difficulties with revenues to the national budget.

The aim of this paper is to evaluate if the current prevention measures against tax evasion, taken at local and unitary level are effective and sufficient to prevent tax evasion in the near future. In order to responsibly evaluate the effectiveness of fiscal measures, a detailed analysis of the process of tax evasion and an identification of the weaknesses of current tax legislation shall be performed. The paper also analyzes the revenues from tax collection in the national budget of the Czech Republic with a special focus on value added tax collection. The analysis of tax collection is focused on the years 2010-12, when deficient VAT collection significantly affected the incomes of the national budget and the global crisis had already relented.

The paper also contains an overview of some specific measures, adopted locally in order to prevent tax evasion by some EU Member States and the action taken commonly on the EU level. Weaknesses and the contribution of each measure adopted are also given in the paper, together with an estimate of their effectiveness.

Some of the member countries of the European Union responded to the global economic crisis by increasing tax rates, which alone has not always led to increased tax revenues. Tax fraudsters escalated the situation by abusing gaps in fiscal legislation for tax evasion. The process of VAT collection is impacted by shortcomings that need to be urgently removed. The paper should assess whether the adopted administrative and legal measures, taken by EU Member States to remedy the deficiencies, will be adequate.

\section{Carousel frauds in the Business Transactions}

Such business transactions are carried out by organized crime groups that abuse the weaknesses at the tax system for the purpose of obtaining unjustified property benefit. The simplest version of tax evasion is associated with the implementation of a business transaction in partnership with a missing entity - so-called missing trader fraud. It is understood that the initial conditions for the application of the reverse charge principle of taxation must be in this kind of trade also respected:
- the supplier and the recipient of the goods shall be a person or entity registered as a value added tax payer,

- the supply and acquisition of goods shall be effected in connection with an economic activity,

- delivery of goods to the recipient country shall have a character of a chargeable event,

- transport of goods shall be terminated in the recipient country.

Taxpayers who supply goods to persons or entities registered for VAT in another EU Member State are entitled to a tax deduction. Recipients are obliged to report and pay VAT upon acquisition of the goods. However, unlike the import of goods from third countries tax is not paid concurrently with the acquisition of goods, but subsequently with the filing of tax returns. If the recipient of the goods meanwhile delivers the goods to a person or entity in another EU Member State he is entitled again for a tax deduction. Tax evasion can arise if the recipient of the goods should be entitled to deduct tax at the next delivery, but the tax on the acquisition remains unpaid, which the current tax system basically allows. Once the tax authority discovers that no payment of taxes has been made, it is usually too late to trace the debtor and collect outstanding taxes.

Most fraudsters do not perform such kind of transactions separately but link them together as a "carousel". In the event that so-called carousel frauds are taking place simultaneously in several EU Member States, tax evasions amounting to hundreds of thousands or even millions of euros are generated. It is very difficult to detect and prove fraud in cases where several carousel transactions for the same or similar products are going on at the same time and where a transaction may even include operators from countries outside the EU. This type of tax evasion is not facilitated by sophisticated methods of fraudsters, or by the inactivity of the customs and tax administration, but is supported by the speed of transactions and limited action readiness of inspection bodies.

\section{VAT Collection in the Czech Republic}

Fraud of this kind began to appear in the EU initially in business with goods having small volume, low weight and high value (dental gold, mobile phones, perfumes) and which could be easily and quickly transported across the borders. In the Czech Republic, however, as well as in neighbouring countries, the subject of tax frauds are such commodities which are massive and voluminous, which are traded in large quantities, which are subject to rapid final consumption and are hardly traceable (e.g. building materials, metallurgical iron, specific types of foods). In comparison with other EU countries a transaction can also have a somewhat different form. The seller reports the supply of goods to another EU member (or non-member) state together with the tax deduction, but it delivers the goods only seemingly or even fails to deliver the goods at all. Then fraudster may claim the tax deduction and sell the goods on the local market at a reduced price. Dozens of empty trucks move daily across the Czech Republic and neighbouring countries for this reason. 
The Supreme Audit Office of the Czech Republic supervised the collection of VAT by the General Financial Directorate in the period from January 2011 to December 2012, and analyzed the procedures for recovery of tax arrears with the following results.

Table 1. Due Value Added Tax in the Czech Republic in billions $\epsilon$.

\begin{tabular}{llll}
\hline Fiscal Year & Reported arrears & Enforced arrears & Rate \\
\hline 2010 & 2.293 & 1.491 & $66 \%$ \\
2011 & 2.749 & 1.892 & $70 \%$ \\
2012 & 3.300 & 2.456 & $73 \%$ \\
\hline
\end{tabular}

Supreme Audit Office of the Czech Republic: Regulation no. $13 \_2$ of 2013

The rapid increase of arrears of VAT totaling of 1007 billion $€$ is apparent from this table. The General Directorate of Finance monitors the process of recovery of arrears on VAT only for amounts exceeding 4 million $€$ for one taxable entity. In the beginning of 2013 a total of 77 taxpayers with arrears of VAT amounting to 1 billion $€$ were registered (about $30 \%$ of the reported amount).

The implementation of monitoring process enables to the General Directorate of Finance to obtain valuable information about significant part of VAT arrears. Enforceability of tax arrears shall likely not to increase significantly because more than half of registered debtors are contactless, are housed on virtual addresses, do not reside at the address listed in the commercial register or have no assets.

Table 2. Enforced and recovered tax arrears in the Czech Republic in billion $\epsilon$.

\begin{tabular}{lll|l}
\hline Fiscal Year & $\begin{array}{l}\text { Enforced } \\
\text { arrears of VAT }\end{array}$ & $\begin{array}{l}\text { Recovered } \\
\text { arrears of VAT }\end{array}$ & Efficiency \\
\hline 2010 & 2.847 & 0.279 & $9.8 \%$ \\
2011 & 3.326 & 0.288 & $8.6 \%$ \\
2012 & 3.953 & 0.318 & $8.0 \%$ \\
\hline
\end{tabular}

Supreme Audit Office of the Czech Republic: Regulation no. 13_2 of 2013

The table shows that the efficiency of tax enforcement was very low and continues to decline. Debt collection is ineffective frequently for the following reasons:

- Owners of indebted companies frequently terminate their business without having paid tax on assets and continue in the same business activities in newly founded commercial entities.

- Statutory authorities of some taxpayers are not active, do not reside at the address listed in commercial register and cannot be directly contacted. Such companies usually do not own executory punishable property.

- Taxpayers purposely change company headquarters and local jurisdiction to avoid the initiation of tax proceedings or its completion.

Investigation carried out by the Supreme Audit Office also showed that debt collection requiring international assistance is even far less effective. The efficiency of recovery of tax arrears in these cases stands at around $1.2 \% .^{5}$

What legislative and administrative provisions can local government rely on if it wants to effectively fight against tax evasion linked to the reporting and collecting of VAT within the EU market?

\section{Current European Measures against VAT fraud}

Tax fraud is considered a form of deliberate evasion of tax which is generally punishable under criminal law and tax evasion generally comprises illegal arrangements where liability to tax is hidden or ignored. VAT fraud reduces budget revenues to EU Member States and creates resources that can be used in criminal activities as well. Carousel fraud is one of the most commonly used type of tax deception with very serious consequences. Application of measures against tax fraud and tax evasion is a frequently debated issue in states facing fiscal difficulties.

Support can be found mainly in Council Directive 2013/43/EU, which allows Member States to modify existing tax principles (reverse charge principle of taxation in the EU market) in those cases where their application may violate fair competition on the market.

The changes should be applied for supplies of goods or services of risk categories (especially susceptible to fraud), where Member States may transfer the tax liability on the entity supplying the goods or providing the services, partially or completely. ${ }^{6}$ What type of measures can the tax administration of the Czech Republic use at present in context with the efforts to increase the efficiency of collection of taxes and elimination of tax evasion?

One measure of this kind, aimed at preventing tax frauds, should be the creation of an electronic register of VAT debtors allowing the identification of potential and/or real VAT fraudsters. Screening of a selected contractual partner, in terms of its ability to pay tax, which should highlight the fiscal risk of the intended business transaction, should in practice precede the formation of any contractual obligation. In this way, the tax authorities would have an incentive to ensure future fulfilment of tax obligations. A significant shortcoming of this method is that the carousel tax fraud proceeds so quickly that the fraudster is listed in the register only after the tax fraud has been administratively and financially closed and the fraudster has usually "disappeared".

Requirement for VAT advance payment by the supplier of goods or the provider of services may also be considered a preventive measure. Prepayments should then be returned to taxpayers at the moment the person or entity liable for payment (recipient of goods or services) effectively pays the tax. This non-systemic measure will surely not be in accordance with the commonly used principle of reverse taxation and therefore may be applicable only temporarily and exceptionally. In the tax systems of Central and Eastern European countries it is occasionally used for transactions with goods for atypical needs or applications (building elements and activities, emission allowances), ${ }^{7}$ especially in cases where an immediate situation requires an immediate reaction. 
Tax audits and the subsequent application of recourses are of course among the necessary but usually less effective measures. Inspection usually allows a scanning of the evolution and consequences of tax evasion, but less frequently the additional enforcement of the due amount and application of recourses. In particular, the application of recourses may be complicated because tax legislation might not be fully harmonized and uniformly interpreted in different EU Member States. The fundamental problem for any tax audit is to verify that a legal person claiming the tax deduction knew or should have known about the criminal intent of the transaction, or whether it acted in "good faith" that the business transaction is in accordance with the law, regardless of whether or not such an act should result in an advantage. ${ }^{8}$ The quality and content of the document certifying that the goods have actually physically left the territory of a Member State of the EU which was therefore entitled to deduct the taxes are very important in these cases.

Unfortunately, neither the existing nor the newly proposed preventive, control and restrictive measures solve the problem of carousel frauds in a systematic and comprehensive manner. Council Directive 2013/43/EU of 22 July 2013 provides EU Member States permission to temporarily change the conditions of use of a previously approved reverse charge tax mechanism, but only for a strictly limited time.

\section{Local Procedures Used to Prevent of Tax Frauds}

National tax administrations modify and implement various legal provisions to reduce the volume of tax evasion and increase tax revenues. Some of these provisions, however, are relatively complicated and their application causes VAT payers unnecessary administrative burden. Many of the envisaged measures were not fully implemented due to the recent global financial crisis. In addition to the measures against the tax fraud, adopted at the European level, certain measures against the tax evasion valid only at the national level are also used. The European Commission recommended some new methods in order to improve the fight against tax fraud, including a modification of the current VAT Directive at the end of 2012. These recommendations were summarized in a document titled "Quick reaction mechanism against VAT fraud" providing the legal base for EU Member States to act against VAT evasion. EU Member States can thus quickly and effectively react against any unexpected situation without an explicit EU legal provision. ${ }^{10}$

Modification of the local tax prescriptions frequently forces taxpayers to change fixed business processes and causes increased financial expenses. Differences in the content and the form of individual arrangements undertaken at the national level also bring the necessity of their mutual harmonization on the common market. EU Member States use most frequently the following measures against tax evasion at the national level:

- Usage of the reverse charge mechanism in a local (domestic) business transactions protects against tax evasion in the form of non-payment of VAT. When supplying goods or services between two local VAT payers, the supplier is exceptionally relieved of the obligation to report and pay VAT, but is also deprived of the opportunity to apply for a VAT deduction. The tax administration does not collect VAT from the supplier but from the recipient and thus VAT evasion should not occur. Usage of the reverse charge mechanism at the local level is particularly suitable for transactions where serious tax evasion is observed, as for example in businesses with emission allowances, IT technologies and some kinds of agricultural products.

- Special provisions regarding the purchaser's guarantee for non-payment of VAT by the supplier are used in the VAT legislation of certain EU Member States. The guarantee is a written declaration by the purchaser stating that they will satisfy the creditor up to the level of a stated financial amount, if the debtor fails to meet his obligation or if other conditions as set out in the letter of guarantee are not met. Taxpayers that fail to discharge their duty properly and in time can even be entered in the register of unreliable VAT payers afterwards.

- The tax administration may also require the drafting of a guarantee or receipt of an initial deposit for newly registered VAT payers. Tax authorities may even revoke the tax registration in the case of non-contact payers or lack of communication.

- Special teams, narrowly focused on tax reporting and financial supervision, are gradually being formed not only by the tax authorities, but also in business circles, especially in banks, financial institutions and multinational corporations. This measure may result in a substantial reduction in the number of the tax evasions, effective supervision of selected entities and improve tax collection.

- Improvements in reporting and report-keeping of special business transactions, such as triangulations, inward and outward processing and temporary admission, shall be also introduced. The current reporting of specific business transactions in the framework of Intrastat is not flexible enough and should be gradually replaced by electronic monitoring. Implementing new IT solutions enabling continuous control of tax collection can be helpful not only for the tax administration, but also for public authorities and business circles. The electronic registration and inspection system may be supplemented with a rating of taxpayers in order to facilitate supervision.

Tax fraud registered in recent years has frequently had the character of organized crime. Most EU Member States defend themselves with appropriate modifications of their criminal law. The legal responsibility of artificial persons was introduced to the criminal code, which means that not only individual persons but also legal entities are liable for lawless behavior. A compulsory penalty of prohibition of business activities as a result of serious tax crime can be imposed in 
some EU Member States.

\section{Conclusion}

This paper can be considered a reaction to the unfavorable situation of value added tax collection within the European Community. The majority of EU Member countries responded to the global economic crisis by increasing VAT rates, which has not always resulted in increased revenues to the state budget. The transformation of the taxation system brought with it the necessity to use different procedures in tax collection than were used in the years before the crisis. Tax fraudsters managed to take advantage of the situation and began to abuse the gaps in the tax legislation for tax evasion. Even though EU Member States have already adopted a number of positive partial tax measures, comprehensive and effective solutions are still lacking.

A comprehensive solution to the problem is still under discussion, but the main points are outlined in a "Green Paper on the Future of VAT". ${ }^{11}$ This document summarizes the main issues that need to be resolved in the near future as follows:

- ensure real respect for the neutrality of the VAT system including comparable tax conditions for both the public and private sectors, as well as multinational corporations,

- unify the conditions for exemption from value added tax and tax deductions in EU Member States,

- finalize the process of harmonization of tax brackets and rates within the single market.

The "Green Paper" is still under discussion in the European committees and governments of EU Member States, sometimes with vague and less differing conclusions. For example, The European Economic and Social Committee provided following opinion: ${ }^{12}, \ldots$ the Committee feels that radical changes should be avoided; instead, a step-by-step approach should be pursued". A systematic and comprehensive solution to the problems related to VAT frauds cannot therefore be expected in a relatively short timeframe.

\section{References}

[1] European Commission: Council Directive 2006/112/EC of 28th November 2006 on the common system of value added tax

[2] European Commission: MEMO/12/609 of 31st July 2012 VAT: Commission proposes new instrument for speedy response to fraud

[3] Harrison, G., Krelove, R. IMF Working Paper 05/218, VAT Refunds: A Review of Country Experience, 2005

[4] Keen, M., Smith, S.: National Tax Journal, vol. 59, no. 4., VAT Fraud and Evasion: What Do We Know and What Can Be Done? 2006

[5] NKÚ Supreme Audit Office of the Czech Republic, Regulation no. 13 2, 2013

[6] European Commission: Council Directive 2013/43/EU of 22nd July 2013 amending Directive 2006/112/EC on the common system of value added tax, as regards an optional and temporary application of the reverse charge mechanism in relation to supplies of certain goods and services

[7] Czech VAT Act No. 235/2004 Coll.: Adjustment of reverse charge procedure in the provision of construction and assembly work embodied .

[8] The Court - Third Chamber: Teleos plc and others v. Commissioners of Customs \& Excise. Judgment of the Court (Third Chamber) of 27th September 2007 case no. C-409/04.

[9] European Commission: Council Directive COM(2012) 428 final, Quick reaction mechanism against VAT fraud.

[10] European Commission: Council Directive COM(2012) 351 final. Communication from the Commission on Concrete Ways to Reinforce the Fight against Tax Frauds.

[11] European Commission: Council Directive COM(2010) 695 final. Green Paper on the Future of VAT Towards a simpler, more robust and efficient VAT system.

[12] European Commission: Official Journal COM(2011) 48 final, Opinion of the European Economic and Social Committee no. 2011/C 318/14 on the Green paper. 